\title{
Pesquisa-formação sobre fake news numa perspectiva crítica: discurso anticiência
}

\author{
Training research on fake news from a critical \\ perspective: anti-science speech
}

\section{Investigación de capacitación sobre noticias falsas desde una perspectiva crítica: discurso anticipado}

\author{
Lucinalva de Almeida Silva \\ Universidade de Pernambuco \\ Marcelo Silva de Souza Ribeiro \\ Universidade Federal do Vale do São Francisco
}

Resumo: Objetivamos neste escrito apresentar um recorte acerca de uma pesquisa-formação que tematizou a questão da fake news e da desinformação desenvolvida com um grupo de doze professoras dos anos finais/Ensino Fundamental no município de Afrânio-PE. Para tanto fizemos um recorte da pesquisa maior, discutindo um dos seis encontros. Embasamo-nos numa perspectiva crítica que dialogou com Freire (1996), Santaella (2019) e Valente (2019). A pesquisa traz a abordagem qualitativa interpretativa, do tipo pesquisa-formação. Como dispositivos recorreu-se a entrevista coletiva, a partir de técnicas grupais. Inferiu-se que o encontro descrito evidenciou a importância de se desenvolver a consciência crítica e participativa nos docentes e discentes visando o enfrenta- 
mento a pós-verdade, "fake news" e comunicação saudável, unindo educação crítica ao diálogo, indo assim de encontro ao discurso anticiência gradualmente, pois o processo é paulatino e exige planejamento e ações sincronizadas.

Palavras-chave: Anticiência. Fake news. Formação. Professor. Tecnologia.

Abstract: In this paper we aim to present an excerpt about a research-training that addressed the issue of fake news and misinformation developed with a group of twelve teachers from the final years / Elementary School in the municipality of Afrânio-PE. To do so, we cut out the larger research, discussing one of the six meetings. We are based on a critical perspective that dialogued with Freire (1996), Santaella (2019) and Valente (2019). The research brings a qualitative interpretative approach, of the type research-training. As devi-

2 ces, a collective interview was used, based on group techniques. It was inferred that the described meeting evidenced the importance of developing critical and participative awareness in teachers and students in order to face the post-truth, "fake news" and healthy comunication, combining critical education with dialogue, thus going against the antiscience discourse gradually, because the process is gradual and requires planning and synchronized actions.

Keywords: Antiscience. Fake news. Formation. Teacher. Technology.

Resumen: En este artículo pretendemos presentar un extracto sobre una investigación-formación que abordó el tema de las fake news y desinformación desarrollada con un grupo de doce docentes de los últimos años / Escuela Primaria del municipio de Afrânio-PE. Para hacerlo, eliminamos la investigación más amplia y analizamos una de las seis reuniones. Nos basamos en una perspectiva crítica que dialoga con Freire (1996), Santaella (2019) y 
Pesquisa-formação sobre fake news numa perspectiva crítica...

Lucinalva de Almeida Silva • Marcelo Silva de Souza Ribeiro

\section{Introdução}

Pensar sobre o discurso anticiência nos direciona substancialmente aos últimos anos, mais precisamente no curso de 2020. Ano em que se acentua a diluição e a descrença em relação às pesquisas e os estudos científicos, o qual tem sido intensamente suprimido pelas crenças, emoções e polarizações, caracterizando a chamada "pós-verdade". Verbete amplamente conhecido em 2016 quando é incorporado ao dicionário Oxford, motivado 1) pela eleição presidencial dos Estados Unidos da América e 2) pelo início da votação para saída do Reino Unido da União Europeia (BREXIT). Desde então, achados de diferentes estudos, apontam que as sociedades democráticas correm grandes riscos em todo o mundo.

Vários líderes, sobretudo políticos neoliberais, conservadores e populistas com matizes autoritários têm chancelado este movimento que nega o rigor do conhecimento cientificamente comprovado, disseminando fake news e teorias da conspiração, a nível nacional e global, nutrindo o ecossistema da desinformação, dando forma a todo tipo de insensatez humana.

Nesse trabalho apontamos que, este panorama, evidencia a insipiência na formação educativa inicial do indivíduo, dimensionando-a na instituição escolar, o que é também consequência da formação inicial docente. Isto é, possivelmente docentes egressos de um ensino superior deficitário, no que diz respeito aos avanços das Tecnologias Digitais da Informação e Comunicação (TDICs) repliquem uma prática pedagógica com essa característica, o que tem comprometido o ensino nesta era. Por fim, defende-se aqui que esse déficit pode contribuir também para a lacuna escolar do ponto de vista de uma educação crítica, cotidiana, dialógica e humanística voltada para o papel emancipador do 
cidadão, à medida que, por conta de uma lacuna na formação (e prática) docente, a escola tenha dificuldades de cumprir seu papel face aos desafios da atualidade, mais precisamente, dar conta de uma sociedade que é afetada pela desinformação.

Nesse sentido, a instituição escola tomada como espaço de construção do conhecimento crítico nos "esperança", pois "aconselhamentos são sempre promissores, principalmente junto aos educadores relativos aos efeitos que o mau uso das redes tem provocado" (SANTAELLA, 2018, p.26). Parece ser emergencial, portanto, evocar a formação, pois há exponencial ênfase em relação ao uso das tecnologias, principalmente com o afastamento social indicado pela Organização Mundial de Saúde (OMS), no qual para o indivíduo as plataformas virtuais funcionam como uma válvula de escape, lá permanecendo por horas como forma de entretenimento. Mais ainda, nesta vertente também foram transferidas para o lar as atividades escolares (ensino remoto emergencial, homeschooling) e laborais (home office).

É neste cenário que se faz determinante articular pesquisa e educação. Pesquisas interventivas se amparam na pesquisa-formação/ação, (LONGAREZZI \& SILVA, 2013). A pesquisa-formação com professores e sua articulação com a representatividade societal e política, própria da escola, acontecem em um processo de superação de formas convencionais de pesquisa, e com isso, trazendo uma nova perspectiva no combate ao discurso anticiência, através do uso consciente das redes midiáticas com ênfase em ambientes educacionais e não educacionais. O conviver tem sido líquido, sobrepondo-se ao real, fato que evidencia a urgência que circunda a formação docente, da qual trata este estudo.

A produção deste escrito resulta de um estudo que foi desenvolvido ao longo de um bimestre com três docentes dos anos finais/ Ensino Fundamental, por meio de encontros reflexivos, contendo 
atividades individuais e coletivas, seguidos de estudos dirigidos que utilizaram cartilhas virtuais, quiz educativos, vídeos, dinâmicas, e a partir destes, a entrevista. Como recursos: telefone celular/ smartphone, "mídia", cartolina, papel ofício e outros. Desse modo, objetivou compreender os processos formativos, no contexto de uma pesquisa - formação para professoras dos anos finais/Ensino Fundamental no município de Afrânio-PE, acerca da fake news e da comunicação disponibilizadas na internet facilitando um processo reflexivo voltado ao desenvolvimento de saberes.

Os saberes docentes se refazem cotidianamente de acordo as emergencialiadades que a educação perpassa. Dentre estas, apropriar-se das minucias e refletir criticamente acerca da proliferação de fake news e desinformação nesta era, objeto emergente ao professor, a escola, a toda a sociedade. Esse cenário elenca a explosão e acesso facilitado às redes sociais, no qual a notícia sai do polo massivo de produção jornalístico em reflexo ao exponencial avanço das tecnologias e, consequentemente a multiplicação de novas plataformas. Estas últimas têm facilitado a produção de todo tipo de conteúdo com o auxílio das tecnologias, baixo custo, larga expansão e engajamento.

A produção de notícias sai do domínio da imprensa especializada e passa para a mão de cidadãos comuns que, de posse de um smartphone podem produzir qualquer tipo de conteúdo livremente e compartilhá-lo em grande escala. Isso, em virtude do barateamento relativo à produção e a disseminação de conteúdos duvidosos sem nenhum tipo de controle ou de verificação. Com esse panorama emergente buscamos nortear este escrito a partir das seguintes indagações: De que modo ocorre à influência da fake news e da comunicação no discurso anticiência na era da pós-verdade? E, diante desse contexto, de que maneira as professoras direcionam a comunicação responsiva na sala de aula? 
Pesquisa-formação sobre fake news numa perspectiva crítica...

Lucinalva de Almeida Silva • Marcelo Silva de Souza Ribeiro

Partiu-se do pressuposto de que a Secretaria Municipal de Educação de Afrânio-PE não adota uma política pública educacional para e nas mídias, visando à apropriação da educação midiática no atual contexto, no qual o conhecimento científico é diluído, um contraponto a estudos empíricos.

Fizemos um recorte de uma pesquisa maior em andamento para dissertação de mestrado, realizada em seis encontros reflexivos, com 12 professoras pertencentes a seis escolas. A pesquisa foi aprovada pelo Comitê de Ética da Universidade de PernambuCo (UPE), com o CAAE 16405019.5.0000.5191. Apreendemos, para este manuscrito, um dos encontros reflexivos, envolvendo três professoras e duas escolas. Nosso estudo, em termos metodológicos, se situa na pesquisa-formação, com abordagem qualitativa interpretativa, centrada numa perspectiva crítica, com foco na descrição da realidade, bem como relatos do processo desenvolvido em sala de aula. Respaldamo-nos teoricamente nos postulados de Ibiapina (2008), Nunes (2019), Freire (1996), Valente (2019), Albuquerque e Kuinam (2019), Longarezi e Silva (2008; 2013) e outros, que abordam também em seus escritos questões relacionadas ao desenvolvimento do conhecimento crítico e da teoria da conspiração, diretamente ligada ao enfraquecimento das instituições democráticas, públicas de direito na atualidade. A relevância da pesquisa-formação na formação continuada de professores pretende impulsionar a reflexão acerca da prática crítico-educativo em favor da autonomia dos educandos.

Para a realização deste escrito, o trabalho foi organizado da maneira que segue: pesquisa e formação de professores: um imenso desafio; crise da verdade e cultura do negacionismo; tessituras metodológicas; arremates principais e, por fim, as considerações. 


\section{Pesquisa e Formação de Professores: um Imenso Desafio}

Sob a ótica de que a condição do professor como participante do seu processo formativo só é possível a partir de uma consciência crítica, Freire (1996) elenca que - na formação permanente dos professores - o momento fundamental é o da reflexão crítica sobre a prática, pois é pensando criticamente a prática de ontem que se pode melhorar a prática seguinte. Para tanto, o próprio discurso teórico, necessário à reflexão crítica, tem de ser de tal modo concreto que quase se confunda com a prática. Nesse sentido, a formação pela pesquisa permite que este possa ter compreensão acerca das informações compartilhadas nas redes, tanto para aprendizagens pessoais, quanto para a vivência da docência. E isso em consonância com sua prática de ensino, produzindo assim saberes e a busca pela verdade dos fatos e incentivando seus discentes a refletirem sobre o que de fato está por trás de cada informação, e o interesse por trás da divulgação de tais informações.

Porém, a pesquisa como processo formativo precisa considerar a realidade do professor e a realidade no qual está inserido.

Embora se reconheça a positividade da utilização da pesquisa como dispositivo de formação, a sua inserção e integração no âmbito do trabalho do professor não tem sido fácil. Vários aspectos contribuem para que esse seja um caminho muitas vezes sinuoso e instável, dentre eles destaca-se: o tipo de pesquisa desenvolvida, a disposição e o interesse dos professores em participar do processo formativo, a disponibilidade de instalações apropriadas, as necessidades da escola e dos participantes (LONGAREZI \& SILVA, 2013, p. 215 e 216). 
O desafio, portanto, segundo os autores envolve vários aspectos tanto estruturais, quanto humanos. Dessa forma, a articulação da pesquisa como processo formativo, importante no enfrentamento a fake news e discurso anticiência, esbarra-se ainda em alguns entraves.

Nessa linha, a ideia de preparar os professores para esse novo momento em que a tecnologia promove a informação, como também a desinformação, baseia-se nos pressupostos de uma troca mais sensível e dialógica, entre os indivíduos - pesquisadores e pesquisados, permitindo maior possibilidade de produção de conhecimento a partir do exercício da escuta do outro, através de suas experiências e refletindo sobre as vivências de cada um. Rompendo com a rigidez entre os participantes da pesquisa que envolve-se como indivíduos investigados, na condição de produtores de conhecimento por meio dos dados fornecidos.

9

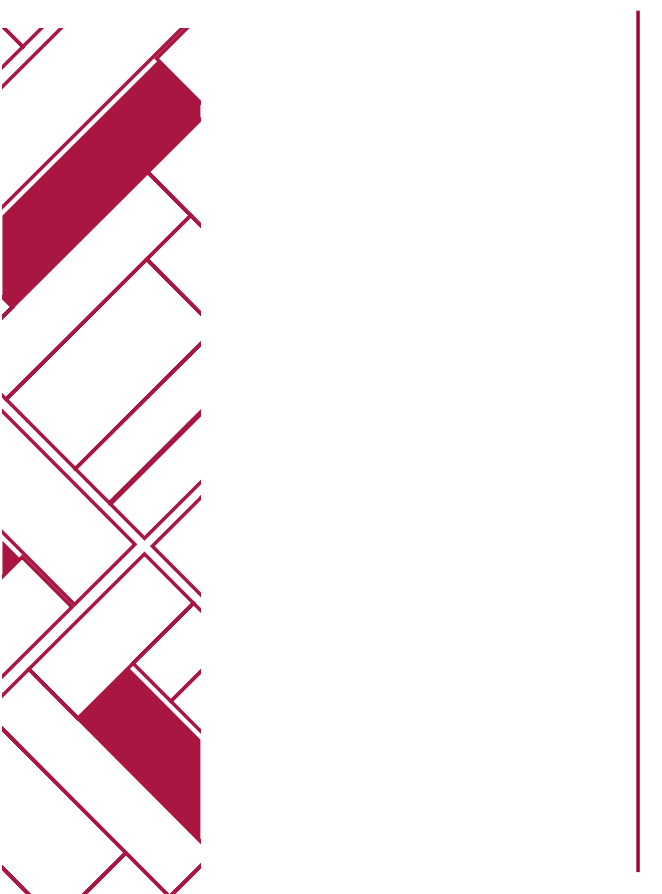

No que tange à formação de professores como processo de aprendizagem da docência e, por isso, processo educativo, a articulação pesquisa-formação representa um processo de superação de formas convencionais de pesquisa e de formação. Historicamente tem-se assistido às pesquisas em educação reduzirem os professores a "amostras" e, portanto, a objetos de estudo. Numa tentativa de superar esse modelo, "pesquisadores da área educacional têm sido desafiados a propor formas de investigação que possam estabelecer uma relação mais orgânica entre suas atividades de pesquisa e ensino, Bueno (apud LONGAREZI \& SILVA 2013, p. 215).

Diante desses desafios, os professores e formadores de opinião precisam traçar estratégias que promovam conhecimento e 
Pesquisa-formação sobre fake news numa perspectiva crítica...

Lucinalva de Almeida Silva • Marcelo Silva de Souza Ribeiro

movimento para tratar a Covid-19 sem a devida validação científica, cujos efeitos colaterais podem atentar a vida.

Essas desinformações são disseminadas pelas plataformas de mídias sociais, como Facebook, Youtube, Twitter e aplicativos de mensagens instantâneas, endossadas por autoridades políticas, dando amplitude e visibilidade a fatos alternativos e teorias da conspiração sob a bandeira de defesa da democracia e de liberdades individuais. Isso colocou de certa forma em perigo, a própria democracia, pois o reconhecimento de autoridades, entre elas a científica, é uma característica que sustenta o modelo de democracia moderna: o caráter racional de avaliação e de tomada de decisão. Neste ínterim, tornou-se corrente a percepção de que experimentamos, atualmente, uma crise epistemológica de grandes dimensões, na qual tem sido considerada sob diferentes pontos de vista. É esse contexto crítico que nos remete aos conceitos de "pós-verdade" e "fake news" (ALBUQUERQUE; QUINAM, 2019).

Como definir o que é verídico? Quem irá definir o que é falso e o que é verdade? Parece que em meio ao temor e ao risco de acontecer uma desordem, uma catástrofe, os indivíduos tornam-se céticos em relação às instituições, e uma alternativa que se apresenta é buscar a verdade por si mesmo. A internet é o caminho lógico para uma sociedade em que o olhar pessoal tem esse tipo de peso, com a aparente falta de mediação, sua possibilidade de participação e a acessibilidade às plataformas e ferramentas torna-a perceptível, sobretudo como suposto espaço mais democrático para se acessar a "verdade" (AUPERS apud ALBUQUERQUE; QUINAM, 2019). É nas redes sociais, portanto, onde a maioria das pessoas passou a se informar sem nenhum filtro crítico, tornando-se, assim, passível de manipulação e alienação.

Nessa linha, vem surgindo, para além do seu exotismo, uma crescente visibilidade adquirida por movimentos negacionistas 
como o terraplanismo, o movimento antivacina e de contestação ao aquecimento global. Esses movimentos dão conta de um desafio inédito que se apresenta à sociedade contemporânea (ALBUQUERQUE; QUINAM, 2019) como crise da democracia. Para os autores, articulado a uma crise democrática, de escala global está uma crise epistemológica, que se traduz pela perda de confiança em instituições fundamentais na sociedade, dentre as quais a própria universidade. No Brasil, essas situações têm sido validadas por governistas neoliberalistas e conservadores, de matiz autoritário, respingando sobre as universidades cortes de verbas, o que inviabiliza a manutenção das ações institucionais e de extensão, além de movimentos e ataques aos professores. Tudo isso ratifica o enfraquecimento e diluição das instituições.

Diante dos pontos levantados, faz-se necessário refletir sobre a formação dos professores, de modo que estes possam fazer face ao enfrentamento a fake news e a desinformação, sobretudo no contexto da sala de aula. Isso se justifica porque as escolas são atravessadas por esses desafios, de modo que são convocadas para proporcionar uma formação que dê conta dessa questão, o que é primordial para a ideia do cidadão politizado e crítico que sabe lidar com os discursos negacionistas e anticiência. Freire enuncia:

Educar é substantivamente formar. Divinizar ou diabolizar a tecnologia* ou a ciência é uma forma altamente negativa e perigosa de pensar errado. De testemunhar aos alunos, às vezes com ares de quem possui a verdade, rotundo desacerto. Pensar certo, pelo contrário, demanda profundidade e não superficialidade compreensão e na interpretação dos fatos. Supõe a disponibilidade à revisão dos achados, reconhece não apenas a possibilidade de mudar de opção, de apreciação, mas o direito de fazê-la (FREIRE, 1996, p. 16). 
Pesquisa-formação sobre fake news numa perspectiva crítica...

Lucinalva de Almeida Silva • Marcelo Silva de Souza Ribeiro

Em conformidade com Freire (1996), é possível afirmar a importância da interpretação, leitura e análise dos fatos para apropriação do conhecimento correto, e utilização das redes com consciência e filtros, contribuindo para uma comunicação responsável e evitando a propagação violenta das notícias falsas e sensacionalistas, sem desconsiderar a importância da ciência e das (TDICs).

Tomando como base esses entendimentos e leituras de mundo, a pesquisa aqui traduzida no recorte possível para o artigo em tela, organizou o caminho, ou melhor, os percursos método, ensejando, assim, suas tessituras.

\section{Tessituras Metodológicas}

Aliou-se a pesquisa-formação, de abordagem qualitativa interpretativa os instrumentos de colheita e construção de dados numa compreensão formativa e autorreflexiva, a pesquisa-formação sugere ao participante pensar não somente na singularidade de sua práxis, mas também como ela se concebe no coletivo, de modo a compreender os sentidos atribuídos as suas ideias viabilizadas por saberes docentes implicados no processo de pesquisa. Desse modo, busca-se oferecer oportunidades de discutir registros, observar progressos alcançados e refletir criticamente a respeito da prática, bem como promover condições para que possa mudar atitudes, compreensões e práticas de colaboração (IBIAPINA, 2008) com o intuito de rever o papel educativo e consciente, capaz de mobilizar-se e impulsionar-se na decisão de perceber-se e de se (re) fazer diante do processo formativo que o envolve, sendo, o centro da pesquisa.

Nesse sentido, foram realizados questionamentos as professoras a respeito da influência da fake news e da comunicação no 
Pesquisa-formação sobre fake news numa perspectiva crítica...

Lucinalva de Almeida Silva • Marcelo Silva de Souza Ribeiro

discurso anticiência na era da pós-verdade e de que maneira as professoras direcionam a comunicação responsiva na sala de aula a partir das novas tecnologias na Educação Básica e suas ambivalências, buscando levá-las a reflexão acerca dos pontos positivos e negativos do uso das ferramentas digitais para a aprendizagem, bem como também, sobre a adequação das mesmas a práxis pedagógica. Para isso, apresentamos as docentes como já mencionado, veículos informativos idôneos e sites de fact checking, na tentativa de obliterar o compartilhamento irresponsivo e a comunicação tóxica, a qual ganha corpo e fortalece a narrativa que se contrapõe ao conhecimento científico.

\section{Arremates Principais}

\section{4}

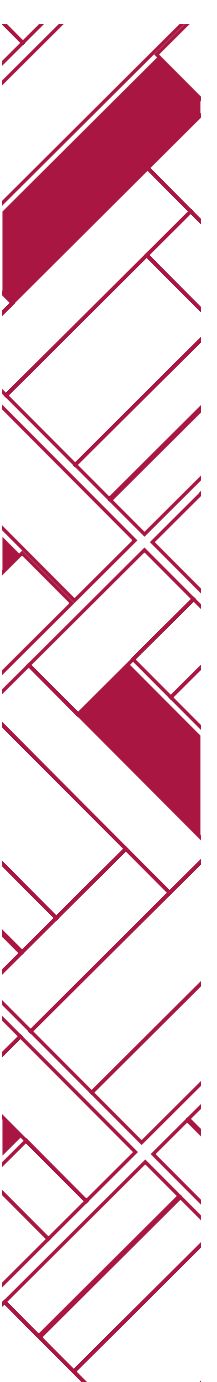

Segundo o sociólogo espanhol Castells (2002), no final do século XX, a estrutura social manifesta-se de várias formas em todo o planeta estando associada ao surgimento de um novo modo de desenvolvimento, o informacionalismo, moldado pela produção capitalista. Nesse sentido, as professoras trazem em suas falas dados que antes não eram tão evidenciados, mas que se fazem fortemente presentes, reverberando o que apontam presenciar nas relações escolares propiciadas por essa nova estrutura social que nos atravessa. Ainda nesta via, o autor salienta que essa nova estrutura social viabiliza acesso instantâneo a informação, e esse fator abre outro precedente, que é o acesso a todo tipo de informação permeada pela comunicação líquida, diluindo a ideia de que ações contra os direitos humanos nos espaços virtuais não serão responsabilizadas.

Os resultados aqui apresentados referem-se as entrevistas oriundas da pesquisa-formação em um dos encontros reflexivos do estudo. 
Denominamos as professoras com os referidos nomes fictícios: a) Comunicação, b) Consciência e c) Cultura.

Primeiro inquirimos as docentes: Quais benefícios à comunicação consciente trouxe a comunidade escolar no que se refere ao conhecimento científico? Agrupamos as respostas da seguinte maneira:

a. Professora Comunicação, "mais consciência acerca da comunicação e manuseio de conteúdos vinculados as mídias sociais".

b. Professora Consciência "protagonismo consciente nas mídias de maior atuação e menos compartilhamento".

c. Professora Cultura "ampliação de novas formas de comunicação por meio da inserção das tecnologias e conceito básico acerca da importância da pesquisa para a ciência".

Analisando o primeiro ponto, é possível dizer que as docentes: Comunicação, Consciência e Cultura concordam que, a comunicação consciente contribui para fortalecer as relações de boa convivência nas mídias, entre discentes e docentes, tanto em ambientes físicos, quanto virtuais educacionais ou não educacionais, enfatizando o conceito básico acerca da ciência e da pesquisa para a sociedade, a exemplo, o campo da medicina. Neste sentido, é preciso que se promova o diálogo mediante a realidade em que vivemos e, que nos utilizemos dele da melhor maneira possível, criticando-o, denunciando disparidades e atuando coletivamente, para que ele se transforme, pensando processualmente e de maneira analítica, nunca dogmática. Essa ampliação da comunicação deve ser utilizada com cuidados e orientações, (VALENTE, 2019) de modo a incentivar o discente à reflexão crítica acerca dos conteúdos consumidos midiaticamente é o início de uma formação consciente. 
Não é possível desvencilhar a escola da sociedade e suas constantes transformações, emergencialidades, pois ela é a representação da sociedade, de modo que é preciso que exerça sua função dialogando com a cotidianidade de sua comunidade, assim a educação crítica se fará presente e emancipadora.

O segundo ponto foi voltado para saber de que maneira a comunicação responsiva e o estudo a respeito da fake news se concebe? Estão presentes nos espaços escolares. Sobre isso, tivemos as seguintes respostas:

a. Professora Comunicação "em desenvolvimento".

b. Professora Consciência "percebo que há uma tímida expansão".

c. Professora Cultura "pouco visualizada. Necessita fazer parte de um projeto que abranja todas as disciplinas do currículo".

De acordo com as respostas do segundo ponto, percebemos que são necessárias ações que desenvolvam e potencializem o uso das tecnologias comunicativas na comunidade escolar, possibilitando a formação de discentes mais conscientes acerca da importância da comunicação saudável e da verificação de fake news nos espaços físicos e virtuais.

Nessa direção, a Base Nacional Comum Curricular (BRASIL, 2018) preconiza um ensino que vá de encontro à proliferação do discurso de ódio sendo tematizado em todos os anos e habilidades relativas ao trato e respeito com o diferente e com a participação ética e respeitosa em discussões e debates de ideias. A respeito da BNCC, o documento versa em sua estrutura impulsionar o debate consciente, de modo a instigar seu desenvolvimento, ao passo que a linguagem líquida propagada pelas mídias, quando ostensiva, causa danos às relações sociais dentro e fora das redes 
e a saúde mental do indivíduo. É preciso que o debate saudável, não violento se dissemine, ganhando corpo por entre estes, nas plataformas educacionais e não educacionais.

A comunicação é o fenômeno que permite a interação entre os indivíduos na sociedade, sendo este o instrumento, por meio do qual nos efetivamos enquanto seres sociais (NUNES, 2019). É o diálogo que encaminha o sujeito à reflexão, este é indispensável na construção da aprendizagem e do saber, a comunicação consciente e crítica é principiada pelo diálogo, este respeitando as peculiaridades e identidades de cada um, dá subsídios ao enfraquecimento da propagação do discurso anticiência, verbalizado pela má qualidade na comunicação disseminado exponencialmente pelas fake news, o qual se fortalece pela insipiência básica de conhecimento acerca da checagem de notícias.

Por último, trouxemos a seguinte pergunta: a comunicação consciente, a fake news e a desinformação estão presentes nos projetos interdisciplinares vivenciados pela escola? Obtendo sequencialmente as seguintes respostas:

a. Professora Comunicação "[...] levando em conta a forte presença das mídias e o acesso que meus alunos têm tido as mesmas nos últimos anos, vejo que a discussão tem acontecido, porém precisamos avançar. Dissociadas da real abrangência".

b. Professora Consciência "sim, mas de maneira mais genérica, a crescente popularização e acesso as mídias indicam a necessidade de um trabalho mais específico, de educação e conscientização acerca da comunicação consciente".

c. Professora Cultura "sim, vejo que há uma compreensão, embora perceba que eles considerem pouco sua importância dentro e fora dos ambientes virtuais e não virtuais". 
Pesquisa-formação sobre fake news numa perspectiva crítica...

Lucinalva de Almeida Silva • Marcelo Silva de Souza Ribeiro

O terceiro e último ponto aqui apresentado indica a presença da comunicação consciente nos projetos interdisciplinares desenvolvidos pela escola, mas evidenciam sua baixa atuação. Para Nunes (2019, p. 50), o diálogo é construído pelos indivíduos através da ação e da reflexão que estes exercem no meio, de modo que, o autor destaca que o processo de ação reflexão é indispensável para a produção legitima de conhecimento. Só através da participação consciente entre os pares é possível construir uma comunicação crítica e consciente.

De modo geral, identificamos através das questões levantadas os benefícios da comunicação consciente no processo de ensino e aprendizagem e que os recursos que possibilitam o desenvolvimento dessa comunicação crítica e consciente ainda não contemplam o desejado no âmbito escolar pesquisado. É preciso incitar os estudantes a se direcionarem a fontes confiáveis, propiciando a eles conhecerem quem publica, se é respeitado, o que omite, a quem direciona e, principalmente o quão é subjetivo, no que diz respeito às parcialidades, passa a ser tarefa primordial para formação de cidadãos em mundo da cibercultura (LEVY, 1999). É essencial que a escola apresente os dois lados oferecidos pelas mídias: por um lado as plataformas digitais nos entretêm, por outro, requerem um pensamento crítico e ético a ser mediado, dentre outros espaços apresentados previamente pelos atores escolares.

\section{Considerações}

Vive-se um momento em que teorias da conspiração alargam-se pela sociedade contemporânea e as universidades e instituições de pesquisa são alvo do discurso anticiência espalhado pela fake news e desinformação, fato crescente e que ganha espa- 
ço e adeptos exponencialmente em todo o mundo, liderado por governistas de matizes neoliberalistas, conservadores, populistas e autoritários que têm alargando seu domínio sobre as nações nos últimos anos, potencializando esses movimentos via fake news. Torna-se, assim, importante o debate público sobre essas questões, sobretudo no campo da educação, principalmente em relação à formação docente.

Dessa forma, este estudo evidenciou compreender os processos formativos, no contexto de uma pesquisa - formação para professoras dos anos finais do Ensino Fundamental no município de Afrânio-PE, acerca da fake news e da comunicação disponibilizadas na internet facilitando um processo reflexivo envolto ao desenvolvimento de saberes experienciais direcionados aos espaços virtuais educacionais e não educacionais, visando o enfrentamento a era da "pós-verdade", "fake news" e de todo tipo de comunicação tóxica. Ademais, buscou destacar a relevância da formação do professor para o uso e direcionamento correto e consciente dos educandos frente às (TDICS), como via de produzir novas formas de comunicação na produção de saberes e conhecimentos e, assim, utilizarem conscientemente a tecnologia presente em seu cotidiano.

Como resultado da pesquisa-formação, infere-se que as professoras apontaram fragilidades quanto à formação continuada. Embora haja uma leve inserção dos fenômenos em estudo nas suas práticas (por meio de projetos em sala de aula ou realizados com a comunidade escolar) a forma de enfrentá-los é ainda insipiente. Consequentemente, essa insipiência afeta a comunicação e comportamentos verbalizados por meio da linguagem líquida nos espaços físicos e/ou virtuais, potencializando a força da fake news em detrimento a ciência.

Em tempo, há muitos estudos a serem construídos nos contextos escolares, que façam frente ao fenômeno da fake news, pós- 
Pesquisa-formação sobre fake news numa perspectiva crítica...

Lucinalva de Almeida Silva • Marcelo Silva de Souza Ribeiro

-verdade e do discurso negacionista. Esse último nega o rigor científico e corrobora negativamente com o avanço de pesquisas em diversas áreas do conhecimento. Mais do que nunca, é preciso unir educação crítica ao diálogo e empatia, primando pela comunicação não tóxica, valorizando a escuta de professores e discentes, num contexto colaborativo atravessado pelos processos formativos, indo assim de encontro ao discurso anticiência paulatinamente, pois o processo é gradual e exige planejamento e ações sincronizadas.

\section{Referências}

AlBuQuerque, Afonso de.; QUiNAN, Rodrigo. Crise epistemológlCA E TEORIAS DA CONSPIRAÇÃO: O DISCURSO ANTI-CIÊNCIA DO CANAL "PROFESSOR terra plana". Revista Mídia e Cotidiano Artigo Seção Temática. Volume 13, NÚMERO 3, P. 83 - 104/DEZEMBRO DE 2019. DisPONÍVEL EM: HTTPS://WWW. RESEARCHGATE.NET/PUBLICATION/337800528_CRISE_EPISTEMOLOGICA_E_TEORIAS_DA_CONSPIRACAO_O_DISCURSO_ANTICIENCIA_DO_CANAL_PROFESSOR_TERRA_PLA -NA_EPISTEMOlogical_.Acesso em: 16 SET.2020.

BRASil, Ministério da Educação. Documento da Base - Conae. DıSPONIVEL EM:HTTP://BASENACIONALCOMUM.MEC.GOV.BR/IMAGES/BNCC_EI_ EF_110518_VERSAOfINAL_SITE.PDF. ACESSO EM: 01 JUL. 2020.

CAStells, Manuel. A sociedade em rede. 6. ed. São Paulo: Paz e Terra, 2002.

iBiapina, Ivana Maria Lopes de Melo. Pesquisa colaborativa: investiGAÇÃO, FORMAÇÃO E PRODUÇÃO DE CONHECIMENTOS. BRASíliA: LíbER LIVRO EDITORA, 2008.136 P.

NUNES, Cleilton Santos. O diÁlogo na construção do Pensamento freiriano. In:PADilha, Paulo Roberto; ABreU, Janaina. (Org.). Paulo Freire 
Pesquisa-formação sobre fake news numa perspectiva crítica...

Lucinalva de Almeida Silva • Marcelo Silva de Souza Ribeiro

EM TEMPOS de faKe NeWS [LIVRO ELETRÔNICO]: ARTIGOS E PROJETOS DE INTER-

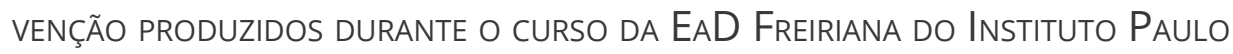
Freire. São Paulo: Instituto Paulo Freire, 2019.

Freire, Paulo. Pedagogia da autonomia: saberes necessários à prática educativa. 25. ed. São Paulo: Paz e Terra, 1996.

léVY, Pierre. Cibercultura. São Paulo: Ed. 34, 1999.

LONGAREZI, Andrea Maturano \& SILVA, Jorge Luiz da. Interface entre PESQUISA E FORMAÇÃO DE PROFESSORES: DELIMITANDO O CONCEITO DE PESQUISA-FORMAÇÃO. IN: VIII CONGRESSO NACIONAL DE EDUCAÇÃO - EDUCERE: formação de professores, 3., 2008, CuRitiba. Anais do VIII Congresso Nacional de Educação - EduCere, Curitiba: Champagnat, 2008, P. 4048 $-4061$.

21

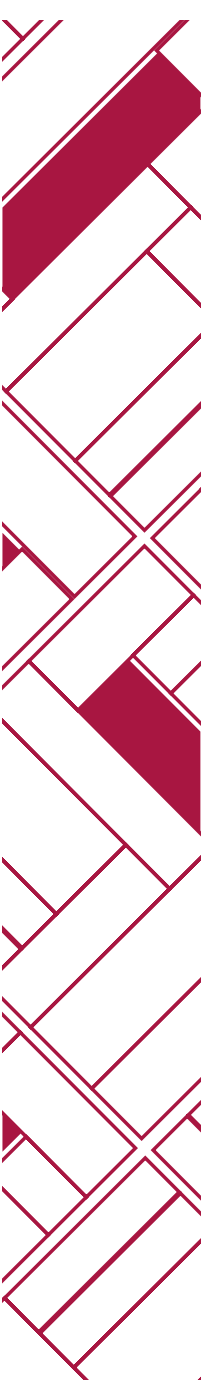
PESQUISA-FORMAÇÃO UM OLHAR PARA SUA CONSTITUIÇÃO CONCEItual e política. Revista Contrapontos - Eletrônica, Vol. 13 - N. 3 - p. 214-225/SET-DEZ 2013.

SANTAELLA, LúCia. A pós verdade É verdadeira ou falsa? Barueri, SP: Estação das Letras e Cores, 2018.

VALENTE, André. Possíveis caminhos para mudança na eduCaÇão brasileira. In: PAdilha, Paulo Roberto; Abreu, Janaina. (Org.). Paulo Freire em TEMPOS DE FAKE NEWS [LIVRO ELETRÔNICO]: ARTIGOS E PROJETOS DE INTERVENÇÃO produzidos durante o curso da EaD Freiriana do Instituto Paulo Freire. São Paulo: Instituto Paulo Freire, 2019. 